\title{
WAVE MODELING WITH SWAN+ADCIRC FOR THE SOUTH CAROLINA COASTAL STORM SURGE STUDY
}

\author{
Christopher J. Bender, Ph.D., P.E., D.CE ${ }^{1}$, William Miller, Ph.D., P.E. ${ }^{2}$, Ashley Naimaster, \\ P.E. ${ }^{3}$, and Tucker Mahoney, P.E. ${ }^{4}$
}

\begin{abstract}
The South Carolina Surge Study (SCSS) used the tightly coupled SWAN+ADCIRC model to simulate tropical storm surge events. The tightly coupled model allowed calculation of wave-induced water level changes within the storm surge simulations. Inclusion of the wave-induced water level changes represents a more physics-based approach than previous methods that added wave setup after model simulations ended. Development of the SWAN+ADCIRC model included validation of water levels to local tidal forcing and for three historical hurricanes — Hazel (1954), Hugo (1989), and Ophelia (2005). The validation for waves did not include Hurricane Hazel because measured data was unavailable. Additional comparisons with WAM model results provided supplemental support to the SWAN model results. Model output applied in comparisons included contour plots of maximum wave parameters, time series of wave parameters at selected locations, and wave spectra.
\end{abstract}

Keywords: waves; modeling; SWAN; ADCIRC; storm surge; flooding

\section{INTRODUCTION}

The South Carolina Surge Study (SCSS) project developed updated storm surge analysis for the 10-percent, 2-percent, 1-percent, and 0.2-percent annual-chance still water elevations or storm surge levels along the entire South Carolina coast. Storm surge includes the cumulative effects of storm winds, wave forces, and tides. The storm surge derived from the SWAN+ADCIRC coupled spectral wave and hydrodynamic model (Luettich, et al. 1992, Booij, et al. 1999, Zijlema, 2010, Dietrich et al. 2011). Within the directly coupled model, the SWAN component develops the offshore and nearshore waves, and the ADCIRC component develops the hydrodynamics and storm surge. The direct coupling of the SWAN+ADCIRC model allows for wave-induced water level changes within the storm surge estimates through gradients in the wave radiation stress passed from SWAN to ADCIRC.

The SCSS team validated the SWAN+ADCIRC model to tides and historical storms with comparisons to major tidal constituents and measured water level and wave data. Following model validation, the team applied the SWAN+ADCIRC model to complete a series of model runs with input data from artificial storms created from the Joint Probability Method Optimal Sampling (JPM-OS) statistical analysis. At the end of this process, analysis of the SWAN+ADCIRC water level data determined the still water elevations for various percent chance occurrence levels. The Federal Emergency Management Agency (FEMA) will use the results of this study to update Flood Insurance Rate Maps (FIRMs) and Flood Insurance Studies (FISs) for the South Carolina counties affected by coastal surge. This report focuses the offshore and nearshore wave model results produced by the SWAN model within the coupled SWAN+ADCIRC model.

\section{MODEL CONSIDERATIONS}

Momentum transmitted to the water column by winds and waves provides the main forcing mechanisms for coastal storm surges (Resio and Westerink, 2008). Thus, the inclusion of wave simulations in coastal storm surge studies incorporates a physical process (wave-related momentum transfer) essential to developing accurate coastal storm surge estimates. Until recently, most coastal surge studies added wave-induced water level changes (wave setup) to the still water level derived from time-dependent circulation-only models to develop storm inundation levels and associated return periods. The absence of a feasible method to combine wave and surge models for state- or region-wide areas, and the lack of computational software and hardware resources to model simultaneously both waves and surge dictated this two-step, independent approach.

\footnotetext{
${ }^{1}$ Taylor Engineering, Inc., 10151 Deerwood Park Blvd, Bldg. 300, Suite 300, Jacksonville, FL 32256

${ }^{2}$ Taylor Engineering, Inc., 10151 Deerwood Park Blvd, Bldg. 300, Suite 300, Jacksonville, FL 32256

${ }^{3}$ Taylor Engineering, Inc., 1675 Palm Beach Lakes Blvd., Suite 210, West Palm Beach, FL 33401

${ }^{4}$ FEMA Region IV, US Department of Homeland Security, 3003 North Chamblee Tucker Road, Atlanta, GA 30341
} 
The SCSS project applied the SWAN+ADCIRC model, which directly couples the ADCIRC model with the SWAN (Zijlema, 2010) wave model developed for unstructured grids. Application of the fully coupled SWAN+ADCIRC model offers some benefits over methods applied in the other previously completed and ongoing studies. The SCSS team conducted test simulations and developed comparisons of SWAN+ADCIRC and WAM model results. The comparisons featured initial model runs with preliminary model mesh and forcing data; however, the results demonstrate generally good agreement between the two different approaches and provide additional validation of the SWAN+ADCIRC model results in nearshore areas with limited measured data.

\section{SWAN+ADCIRC WAVE MODELING SYSTEM}

The SWAN wave model component of the SWAN+ADCIRC model applies the same mesh developed for the ADCIRC circulation model component. Figure 1 shows the mesh extent and bathymetry near South Carolina. To allow SWAN to simulate the offshore and nearshore waves more accurately, the mesh development team added resolution to offshore and nearshore areas where ADCIRC generally does not require such resolution. In addition, the mesh development team added mesh node locations to resolve the active wave breaking zones. Generally, 3-mile (mi) deep ocean mesh resolution transforms to 1,500-foot (ft) resolution for the continental shelf and 350- $\mathrm{ft}$ resolution in nearshore areas with active wave breaking zones.

Dietrich et al. (2011) provides a general description of the SWAN spectral wave model within the SWAN+ADCIRC model. In brief, SWAN applies a wave action balance equation to predict the wave action density spectrum in geographical space. The model accounts for depth- and current-induced refraction and changes to the wave number caused by variations in mean current and depth. A source term within the SWAN model accounts for wave growth by wind; wave action lost due to whitecapping, surf breaking, and bottom friction; and wave action exchanged between spectral components in deep and shallow water through non-linear effects. Booij et al. (1999) provide descriptions of SWAN parameterization of the above terms and processes.

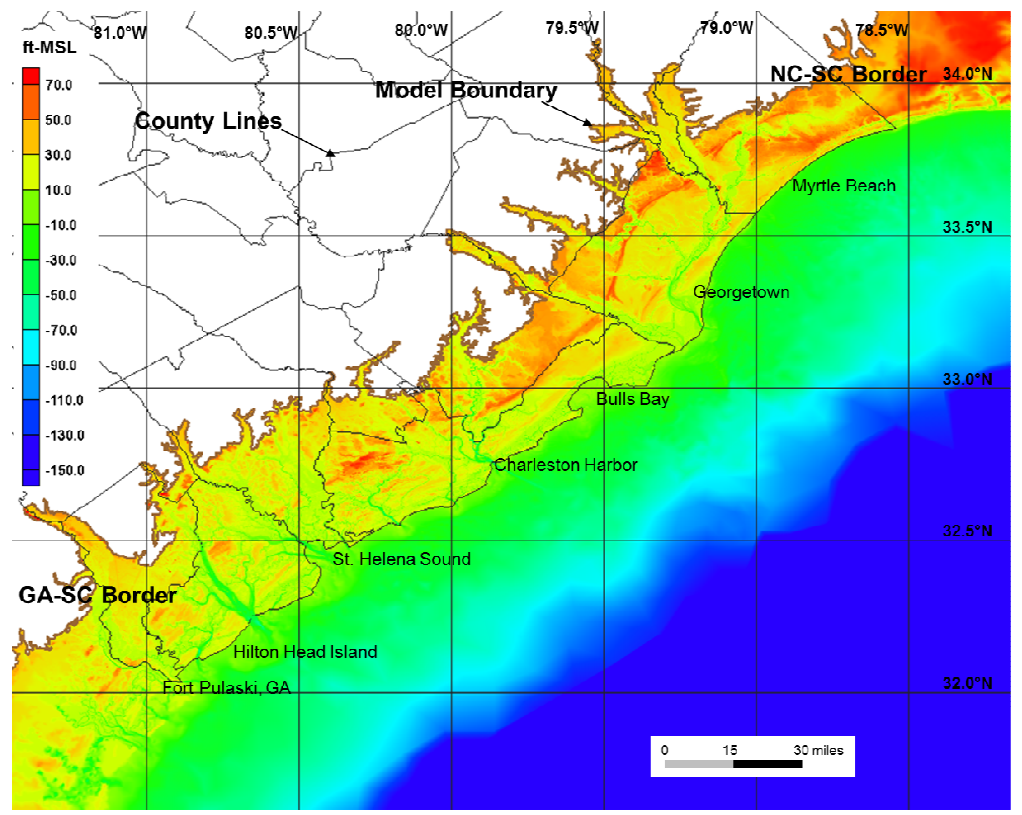

Figure 1: SWAN+ADCIRC Model Bathymetry for South Carolina.

The ADCIRC model component of the SWAN+ADCIRC model supplies SWAN with the required input forcing data - wind speeds, water levels, and currents computed at the vertices — at the given time step. ADCIRC interpolates input wind fields spatially and temporally, projects these winds to the computational vertices, and then passes the wind fields to SWAN. SWAN applies water levels and ambient currents computed in the ADCIRC model component to recalculate the water depth and all related wave processes such as wave propagation and depth-induced breaking (Dietrich et al., 2011). 
The ADCIRC and SWAN model components in the SWAN+ADCIRC model run in series on the same local mesh and core. The two model components "leap frog" through time, each model forced with information from the other model (Dietrich et al., 2011). The sweeping method employed by SWAN to update the wave information at the computational vertices allows SWAN to employ much longger time steps than ADCIRC. Thus, the SWAN time step usually defines the coupling interval between the SWAN and ADCIRC models (Dietrich et al., 2011). SWAN+ADCIRC model testing employed SWAN time steps from 10 to 30 minutes and an ADCIRC time step of 3 seconds. Sensitivity studies completed by the SCSS project team verified that a 20-minute SWAN time step produced reasonable model results and model coupling near the South Carolina coast

The SCSS project team executed SWAN within the SWAN+ADCIRC model in non-stationary mode with 36 directional bins and 31 frequency bins. The maximum and minimum frequency bins equal 0.5476 and $0.0314 \mathrm{~Hz}$. SWAN model runs employed the third-generation mode with the default Komen formulation (GEN3 KOMEN) and the wave growth term of Cavaleri and Malanotte-Rizzoli with default settings. The SWAN simulations applied the third-generation Komen formulation for whitecapping (WCAP KOMEN) with default settings. Model simulations applied the SWAN model default settings for breaking (BREAKING), with triad interactions turned off. Sensitivity runs documented that the removal of triad interactions had a minimal effect on wave heights with peak periods changing by about 1 second in some instances.

The SCSS project SWAN model applied the Madsen et al. (1988) friction formulation (FRICTION), one of three bottom friction formulations available in the SWAN model. The Madsen formulation within SWAN allows spatially varying roughness lengths to define the bottom friction coefficient. The SCSS project team applied a subroutine within the SWAN+ADCIRC model to calculate roughness lengths from the Manning's $n$ friction coefficient assigned to each mesh node for the ADCIRC model. The Manning's n values assigned to each mesh node come from the National Land Cover Data (NLCD) data set developed by the United States Geological Survey (USGS). The SCSS project ADCIRC model component applied a minimum Manning's n value for open water conditions equal to $0.02\left(\mathrm{~s} / \mathrm{m}^{0.33}\right)$. The SCSS project SWAN model component applied a minimum Manning's $\mathrm{n}$ value $(0.03)$ for open water conditions. This value matches the Manning's $n$ value applied for open water conditions in the recently completed Texas Storm Surge Study (TSSS) nearshore wave modeling. The TSSS conducted extensive evaluations and comparisons of nearshore wave model results and wave data measured during hurricanes Ike and Gustav. While South Carolina and Texas do not feature the same offshore bathymetry or sediment characteristics, the general continental shelf and sediment characteristics should allow consideration of the Texas results given the lack of wave data available in South Carolina. Application of different Manning's n values in the ADCIRC and SWAN model components proves reasonable because ADCIRC bases frictional dissipation on a mean, depth-averaged current and SWAN bases fictional bottom dissipation on a root-mean-square bottom orbital velocity.

The SCSS project model runs applied the backward space, backward time (PROP BSBT) numerical scheme (non-default). Because The BSBT applies a lower order numerical scheme than other higher order solution options, it can produce more numerical diffusion than other options. However, due to the SCSS Project domain size and mesh characteristics, the BSBT provided the most robust approach. The convergence criteria (NUM) applied in the SWAN component requires that $95 \%$ of the points in the model must meet a convergence criterion with a maximum number of iterations equal to six. The convergence criteria applied follows guidance from the University of Notre Dame (Casey Dietrich, model co-developer). The SCSS team conducted numerous model sensitivity runs to verify that a maximum iteration number equal to six provided reliable model results without the extra computation time required by additional iterations. The sensitivity tests showed that the SWAN model produces very similar wave conditions for time step and iteration values equal to 20 minutes and 6 iterations versus 10 minutes and 15 iterations.

The SWAN model accounts for wave refraction only in the nearshore area of the South Carolina coast. With global refraction applied in the SWAN+ADCIRC model, the large node spacing in the open ocean and around features far away from the study area (Bahamas Banks, Bermuda, for example) can cause SWAN to concentrate energy and develop unrealistic wave heights (Dietrich et al., 2011). To counter this problem, the SWAN+ADCIRC model team developed a procedure to set up a SWAN+ADCIRC run with refraction turned on only in a high-resolution sub-region of the model mesh (Dietrich et al., 2011). This procedure allows nearshore refraction in the area of interest — near the South Carolina coast - and excludes refraction in deep water (where refraction should not transform 
the waves) or nearshore areas outside the region of interest. The SCSS Project team applied the "refraction region" procedure in the SWAN+ADCIRC model runs.

\section{WAVE MODEL VALIDATION}

The wave model validation compares wave model results to measured wave data from hurricanes Hugo (1989) and Ophelia (2005). Figure 2 - from the NOAA Coastal Services Center mapping application - plots the tracks of the two wave validation storms applied in the SCSS project with storm intensity indicated by color. Notably, even in the absence of available wave data, the SCSS project team selected Hurricane Hazel (1954) as a water level validation storm. The SCSS project team executed SWAN+ADCIRC simulations for each storm, and processed and compared the wave model output to available measured data. Unfortunately, only limited data exist for hurricanes Hugo and Ophelia. The following sections present simulated wave conditions for each storm (SWAN+ADCIRC) with comparisons to available data.

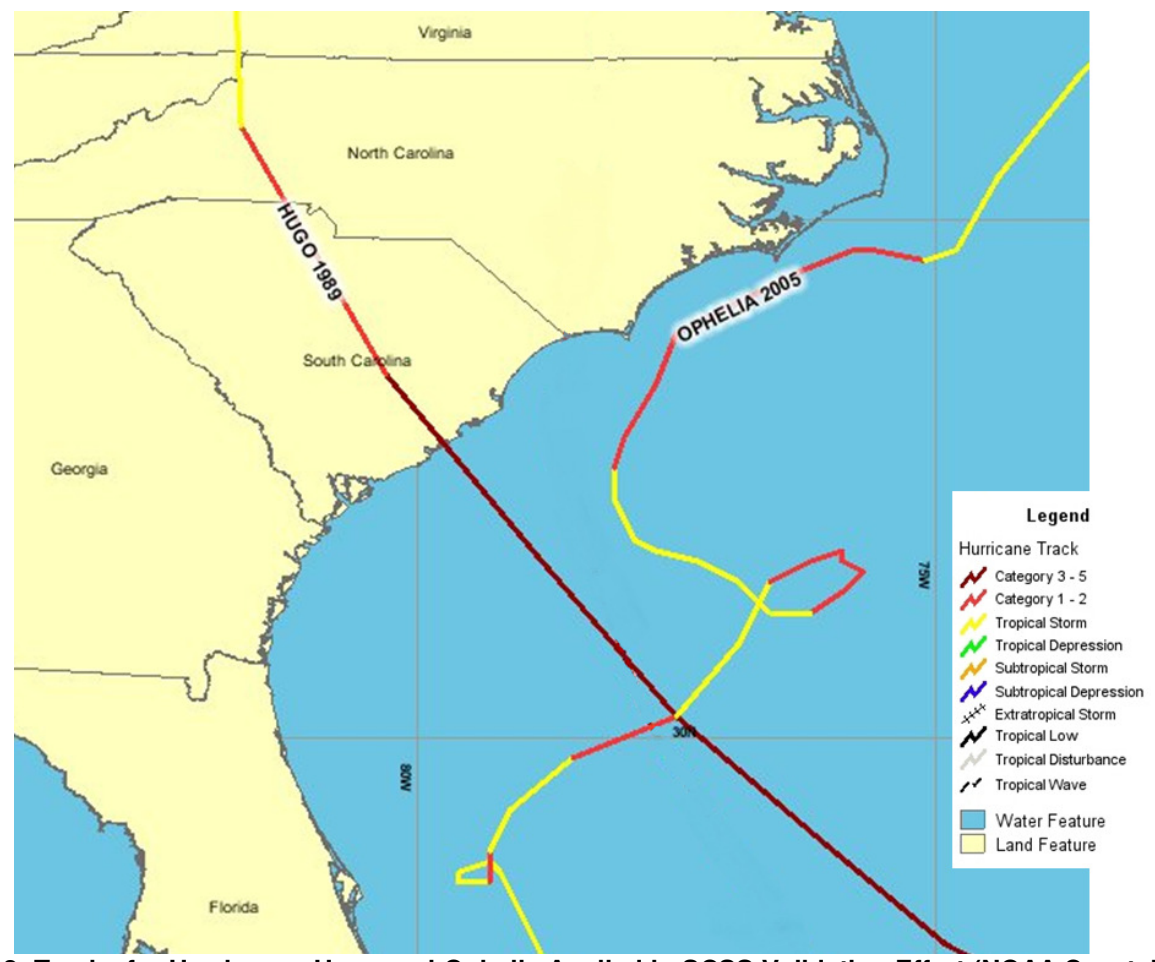

Figure 2: Tracks for Hurricanes Hugo and Ophelia Applied in SCSS Validation Effort (NOAA Coastal Services Center Map).

\section{Hurricane Hugo (1989)}

Hurricane Hugo made landfall on September 22, 1989 as a Category 4 (Saffir-Simpson scale) Hurricane at Sullivan's Island, South Carolina northeast of Charleston. The National Hurricane Center (NHC, 1989) estimated sustained wind speeds of $138 \mathrm{mph}(120 \mathrm{knots})$ at landfall. The track of Hurricane Hugo (Figure 2) and the counter-clockwise rotation of the hurricane wind field resulted in the largest surge and wave heights in areas northeast of Charleston, South Carolina. Figures 3 and 4 show plots of the maximum wave heights and mean periods at maximum wave height in the Atlantic basin for the SWAN+ADCIRC simulation of Hurricane Hugo. The SWAN+ADCIRC model runs included refraction only in the nearshore of the South Carolina coast.

The plots contain vectors that show the mean direction at maximum wave height. Figure 3 shows a swath of large wave heights (in excess of $40 \mathrm{ft}$ ) as the storm traveled toward the South Carolina coast. Wave heights diminish with distance away from the storm and wave directions generally point northwest. Figure 4 shows mean periods at maximum wave height approaching 10 to 14 seconds in the offshore area. 


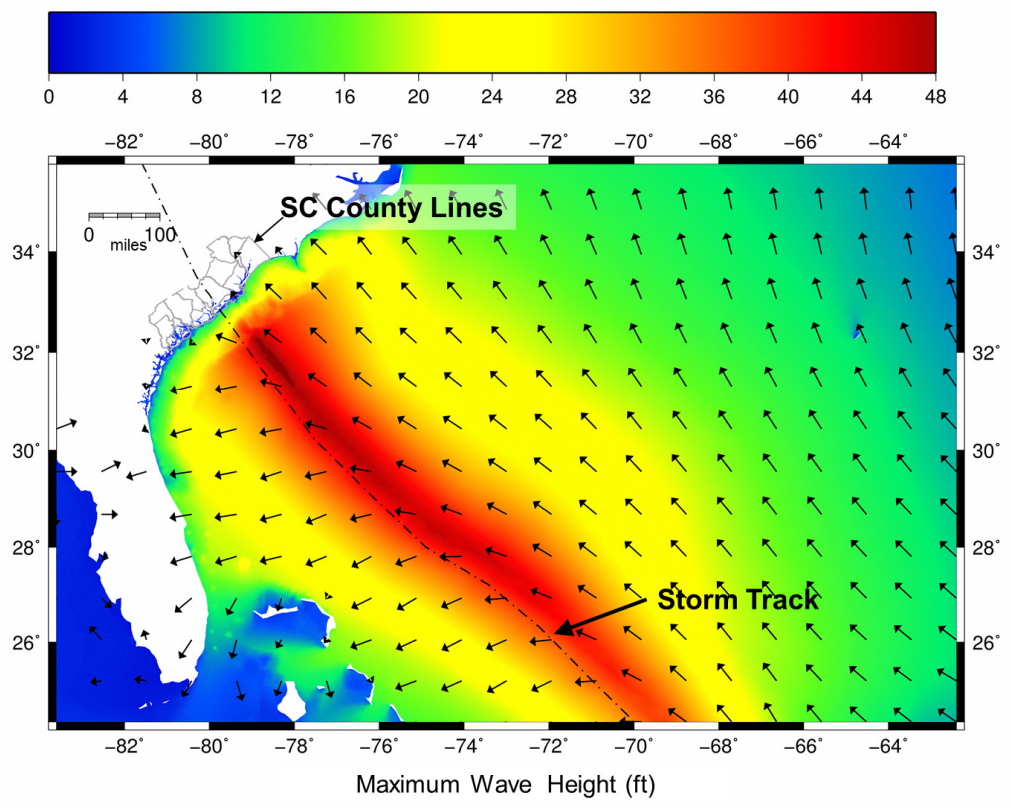

Figure 3: Maximum Wave Heights (ft) in the Atlantic Basin Simulated by SWAN+ADCIRC for Hurricane Hugo.

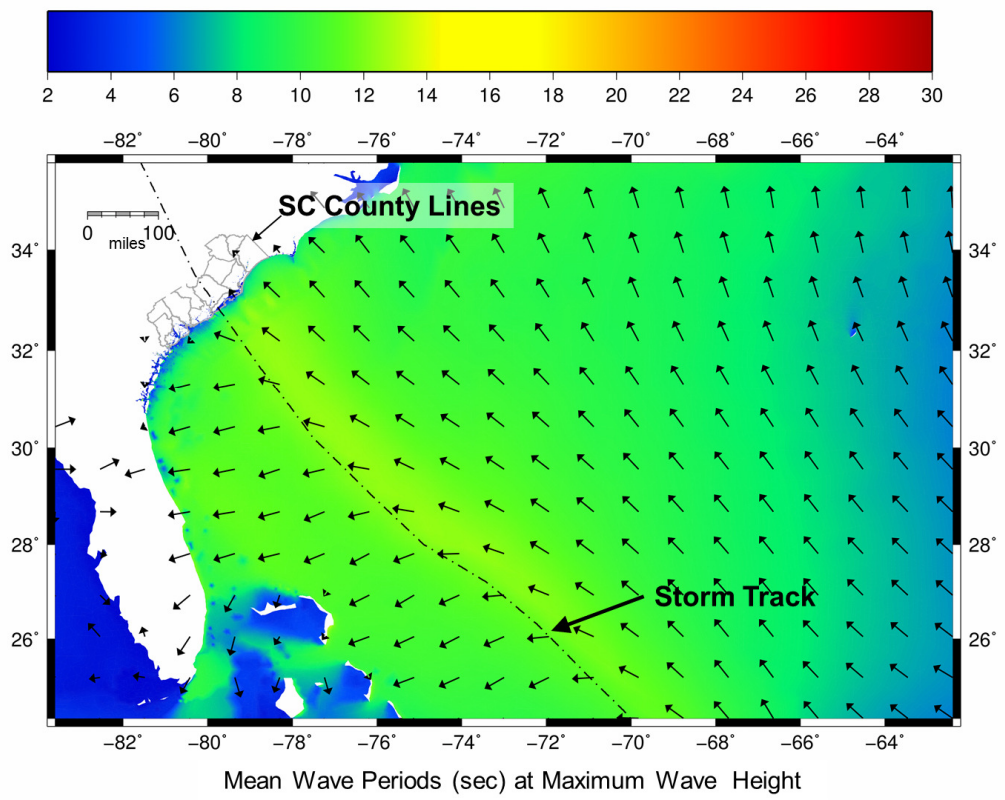

Figure 4: Mean Wave Periods (sec) at Maximum Wave Height in the Atlantic Basin Simulated by SWAN+ADCIRC for Hurricane Hugo.

Figures 5 and 6 show plots of the maximum wave heights and mean periods at maximum wave height near South Carolina for the SWAN+ADCIRC simulation of Hurricane Hugo. Figure 5 highlights the influence of the nearshore bottom on the waves as wave energy dissipation occurs through steepness and depth-limited breaking. Notably, the large offshore wave heights cause wave breaking to occur well offshore of the coast. Depth-limited breaking effects continue in the nearshore zone, which experiences wave heights in the 10-ft range in areas with broad, shallow nearshore areas. Figure 5 shows almost 15$\mathrm{ft}$ wave heights with steeper nearshore profiles near Myrtle Beach, Florida. Figure 6 shows large mean wave periods $\left(\mathrm{T}_{\mathrm{m} 01}\right)$ at maximum wave height in the nearshore zone offshore of South Carolina during 
Hurricane Hugo. The figure shows small pockets with lower mean periods near Myrtle Beach. The figures show waves moving onshore at peak conditions along the entire coast.

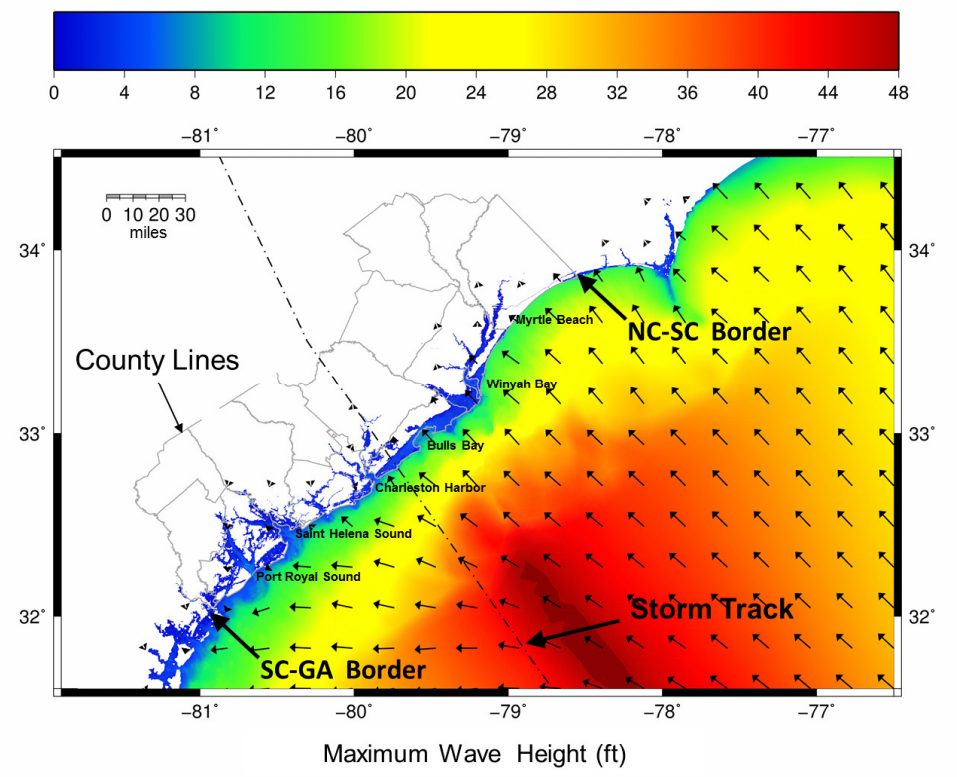

Figure 5: Maximum Wave Heights (ft) near South Carolina Simulated by SWAN+ADCIRC for Hurricane Hugo.

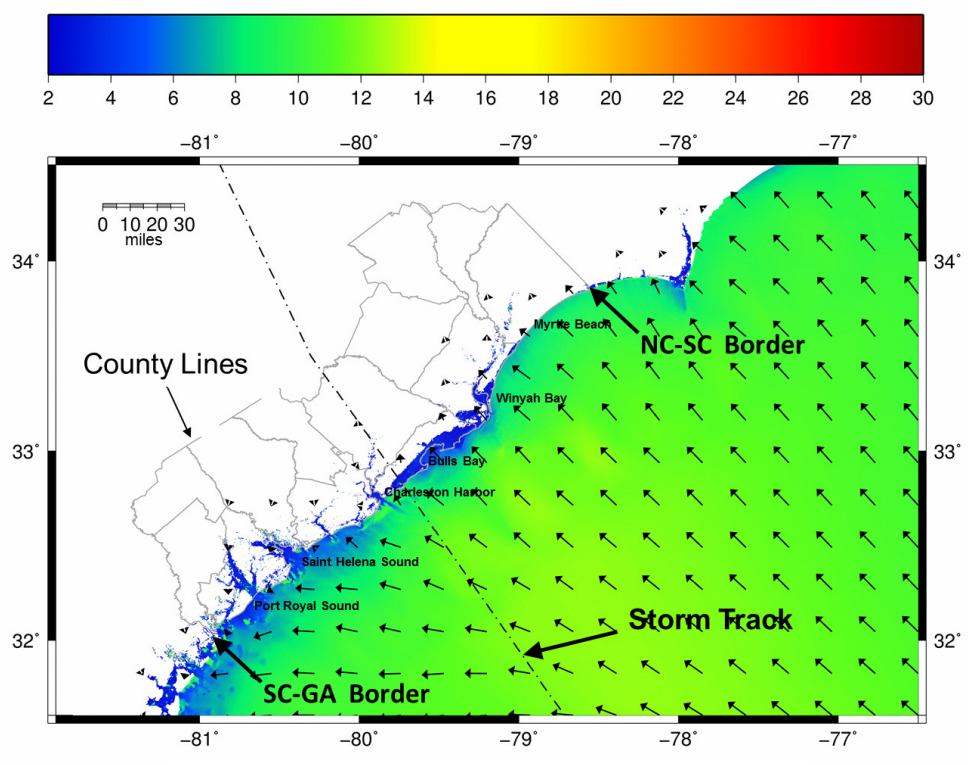

Mean Wave Periods (sec) at Maximum Wave Height

Figure 6: Mean Wave Periods (sec) at Maximum Wave Height near South Carolina Simulated by SWAN+ADCIRC for Hurricane Hugo.

Figure 7 presents the peak wave periods at maximum wave height near South Carolina for the SWAN+ADCIRC simulation of Hurricane Hugo. The plot shows higher wave periods than Figure 6 (expected behavior) with some instances of peak wave periods changing from swell to locally generated sea conditions near Myrtle Beach. Figure 7 shows isolated inland locations where the peak wave periods at maximum wave height exceed 20 seconds. These isolated locations generally lie near channel banks and other regions with steep topographic gradients and produce wave heights of less than $1.5 \mathrm{ft}$. A more detailed review reveals that the cumulative effect of coupling the waves with the surge in the modeling system produces reasonable wave-induced water level changes at these locations, despite the unusually high peak periods. The ADCIRC model applies the SWAN radiation stress gradients based 
on the individual spectral components and not the bulk - peak or mean — parameters. Therefore, the occurrence of energy at the tail of the spectra within a small frequency range should not significantly influence the overall spectral contribution of wave-related momentum to the ADCIRC model. Notably, the STWAVE models applied for the completed Louisiana Storm Surge (LSSS) and TSSS studies also exhibited isolated regions where the peak wave periods differed greatly from surrounding values.

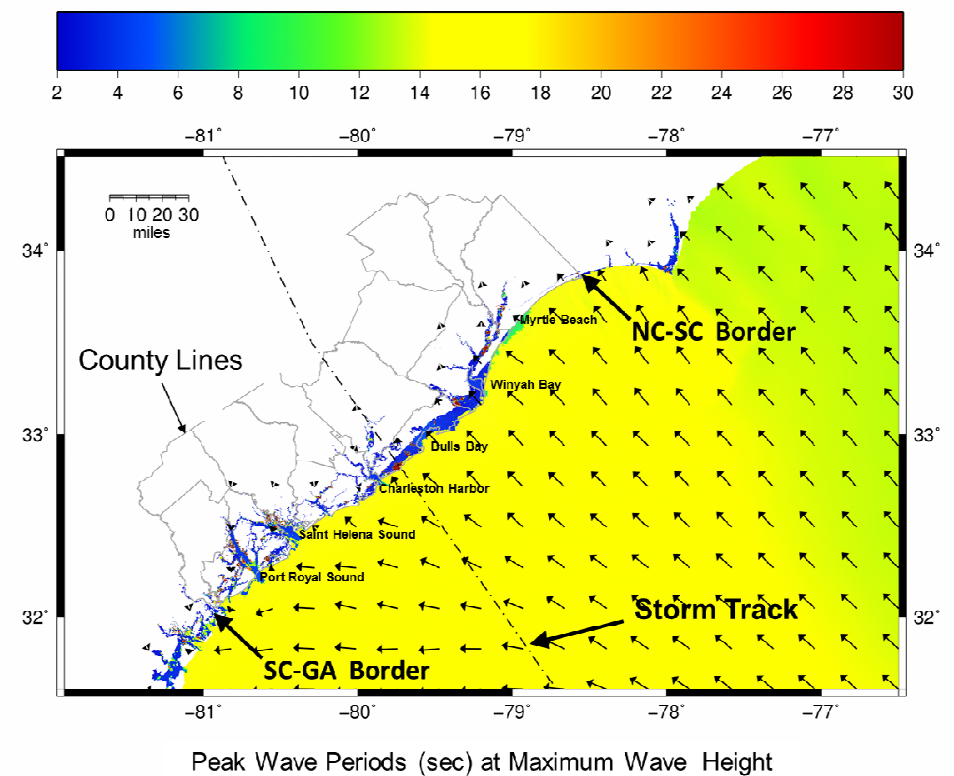

Figure 7: Peak Wave Periods (sec) at Maximum Wave Height near South Carolina Simulated by SWAN+ADCIRC for Hurricane Hugo.

During the SCSS project effort, communications with the model developers suggest that the high peak periods may result from noise at the low-frequency end of the wave spectra. Notably, a recent paper by Dietrich et al. (in revision) presents a method that greatly reduces or removes the high peak period values with little degradation of model results. These isolated high peak wave periods point to the difficulty in simulating waves in inundated inland areas with shallow water depths and significant wind forcing. Figure 8 plots the maximum radiation stress gradient values calculated by SWAN and passed to the ADCIRC component of the SWAN+ADCIRC model. The plots show expected features with the largest gradients in the main wave breaking zones along the coastline and some offshore and inundated inland areas where significant wave breaking occurs.

Very limited wave measurement data exist near the South Carolina coast for Hurricane Hugo. Measurements at National Data Buoy Center (NDBC) Stations 41002 (S. Hatteras, 250 nautical miles [nm] east of Charleston, South Carolina) and 41008 (Grays Reef, $40 \mathrm{~nm}$ southeast of Savannah, Georgia) provide measured wave height and period data during the passage of Hurricane Hugo. Figure 8 shows output points selected for wave model result comparisons with both NDBC Station and SCSS Project output station locations plotted. The selected locations constitute a subset of comparison points scattered in the South Carolina project nearshore area and NDBC station locations.

Figures 9 and 10 provide time series comparisons of the wave heights and peak wave periods for the NDBC Station 41002 measurements and the SWAN+ADCIRC simulation results starting on September 20, 1989 (Day 19 on x-axis) during Hurricane Hugo. Hurricane Hugo passed south of Station 41002; the station data indicate large wave heights and peak wave periods. The figures show good agreement between simulated and measured wave heights and peak wave periods during the threeday period of SWAN output. Figures 11 and 12 provide time series of the wave heights and peak wave periods for the NDBC Station 41008 measurements and the SWAN+ADCIRC simulation results.

Hurricane Hugo passed well north of Station 41008; the station data indicate lower wave heights and more scatter in the peak wave periods than Station 41002 data. Figure 12 shows generally good agreement for measured and simulated peak wave periods during the three-day period of SWAN output. However, the SWAN simulation predicts wave heights that exceed those measured at Station 41008 by 
about $3 \mathrm{ft}$ at peak conditions. The oscillations in the plot for Station 41008 peak period measurements indicate some significant wind-generated short period energy. The lack of measured wave spectra data (detailed information on different frequencies and directions) limits interpretation of the disparity between the measured and simulated wave heights. Certainly, the large distance from the measurement station to the storm makes accurate simulation of the wind field, which drives wave development, more difficult. Overall, given the location southwest of the study area, the overestimated wave height does not cast doubt on the capability of the SWAN model to develop reasonable wave conditions in the study area.

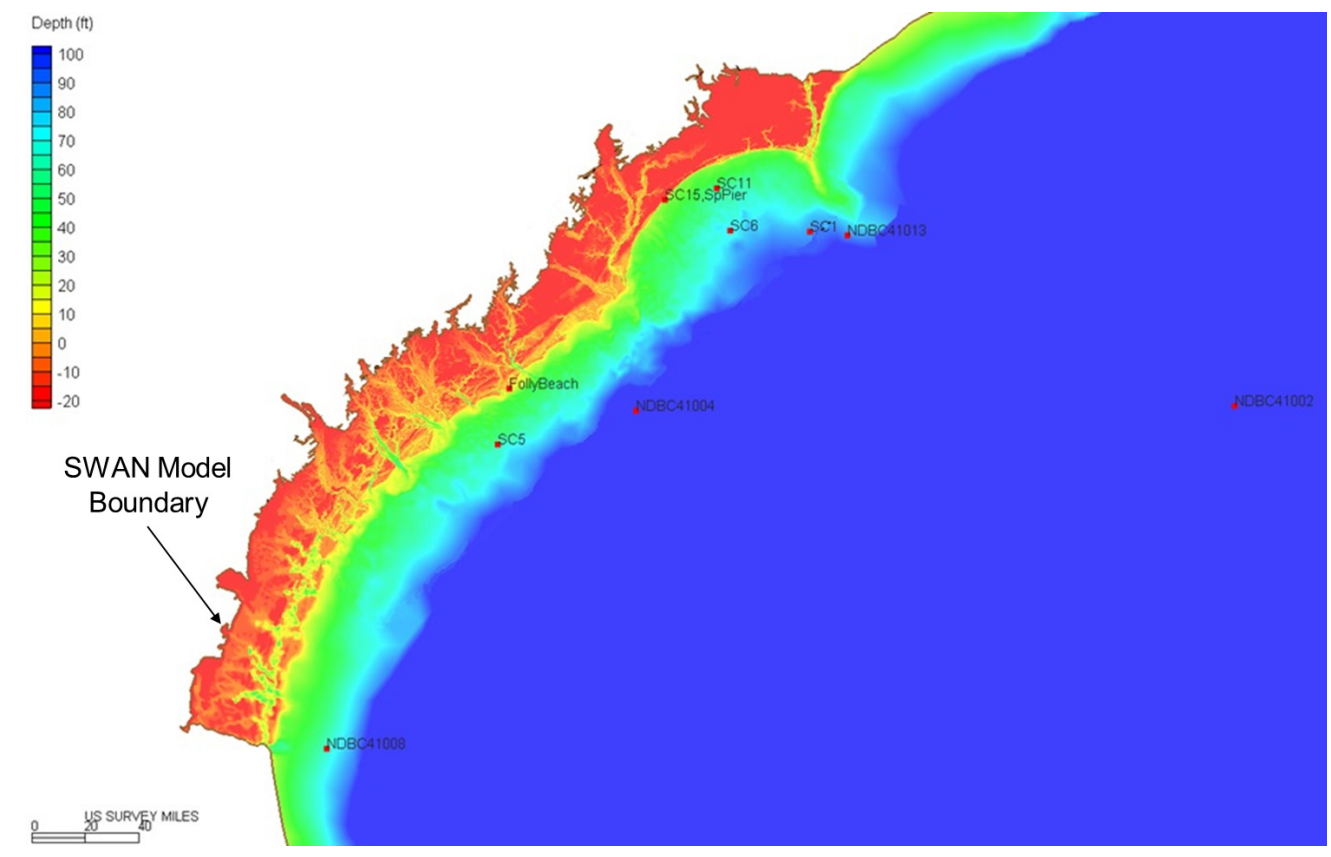

Figure 8: Location of Selected Output Points for Wave Model Comparisons.

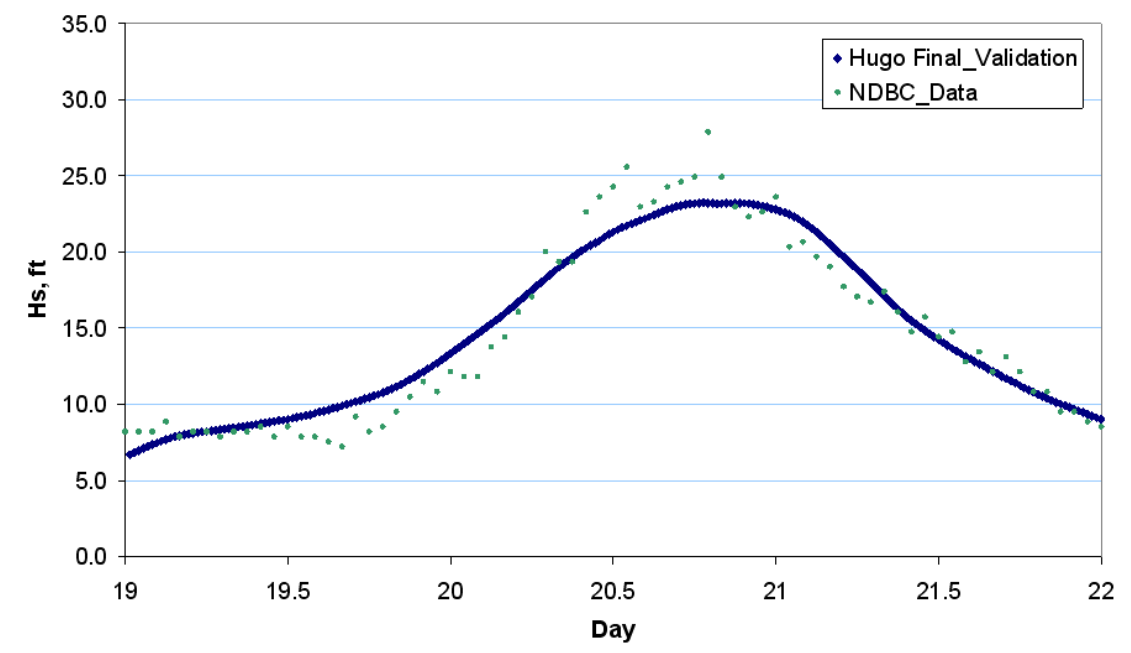

Figure 9: Comparison of SWAN+ADCIRC Simulation Results and NDBC Station 41002 Wave Height Measurements for Hurricane Hugo. 


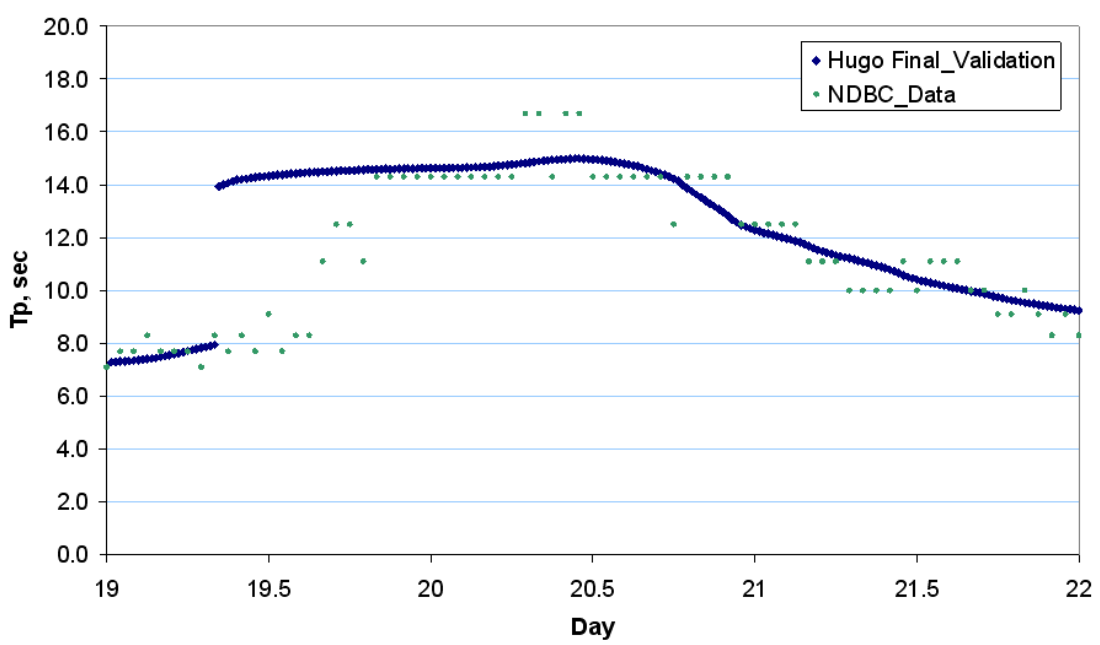

Figure 10: Comparison of SWAN+ADCIRC Simulation Results and NDBC Station 41002 Peak Wave Period Measurements for Hurricane Hugo.

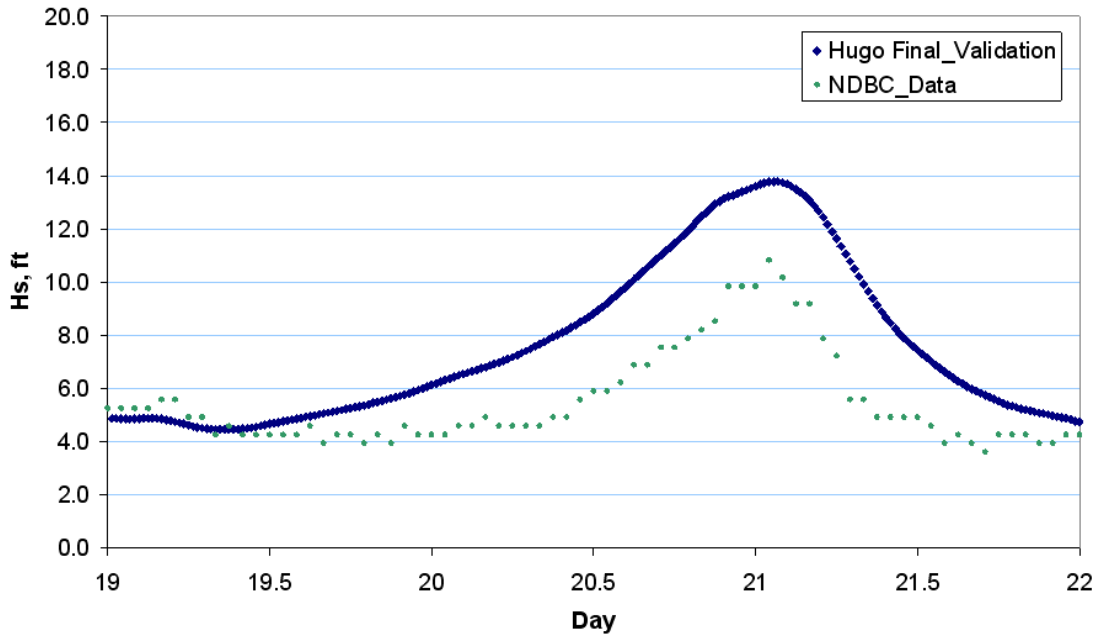

Figure 11: Comparison of SWAN+ADCIRC Simulation Results and NDBC Station 41008 Wave Height Measurements for Hurricane Hugo.

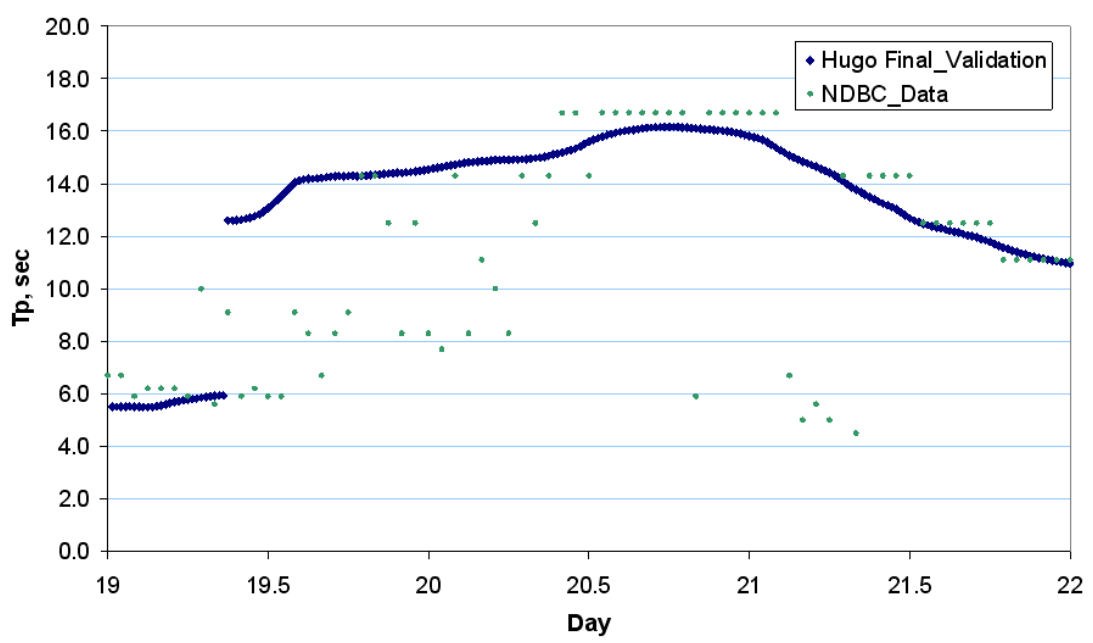

Figure 12: Comparison of SWAN+ADCIRC Simulation Results and NDBC Station 41008 Peak Wave Period Measurements for Hurricane Hugo. 
Hurricane Ophelia (2005)

Upgraded (for the fourth time) from a tropical storm to a hurricane on September 14 (Beven and Cobb, 2005), Hurricane Ophelia passed the coast of South Carolina on September 13 and 14, 2005. During this time, the northern portion of the 57 mi-wide $(50 \mathrm{~nm})$ eye reached the coast of North Carolina near Cape Fear; however, the actual center of circulation stayed offshore (Beven and Cobb, 2005). Ophelia moved parallel to the North Carolina coast for much of September 14 and 15, with peak winds reaching $86 \mathrm{mph}$ (75 knots), although these winds remained offshore (Beven and Cobb, 2005). The meandering track of Hurricane Ophelia (Figure 2) did not make a direct landfall in South Carolina. Because the storm skirted the South Carolina coast and did not make direct landfall, the magnitude of the measured surge and wave levels for Hurricane Ophelia do not match the levels of Hurricane Hazel or Hurricane Hugo. However, the meandering track of Hurricane Ophelia caused elevated water levels to occur for a long duration.

Figures 13 and 14 show plots of the maximum wave heights and mean periods at maximum wave height near South Carolina for the SWAN+ADCIRC simulation of Hurricane Ophelia. The results show very different features than the maximum conditions for Hurricane Hugo. Figure 13 shows wave heights in the 20-ft range offshore of South Carolina with maximum waves moving in many different directions, but moving onshore at the coast. In the nearshore zone, maximum wave conditions generally moved west or northwest with wave heights less than $10 \mathrm{ft}$, except in the Myrtle Beach area where the plots indicate 15 -ft maximum waves.

Figure 13 indicates the largest waves occurred off the North Carolina coast with wave heights over $30 \mathrm{ft}$. Figure 14 shows mean wave periods $\left(\mathrm{T}_{\mathrm{m} 01}\right)$ at the time of maximum wave height in the nearshore zone offshore of South Carolina during Hurricane Ophelia. The figure shows mean wave periods at maximum wave height approaching 12 to 14 seconds in the entire South Carolina nearshore area.

Similar to the results for Hurricane Hugo, the Hurricane Ophelia results included isolated locations with abnormally high peak wave periods. Again, these isolated locations lie near channel banks and other regions with steep topographic gradients with waves generally less than $1.5 \mathrm{ft}$ and likely result from model noise at the low frequency end of the wave spectra.

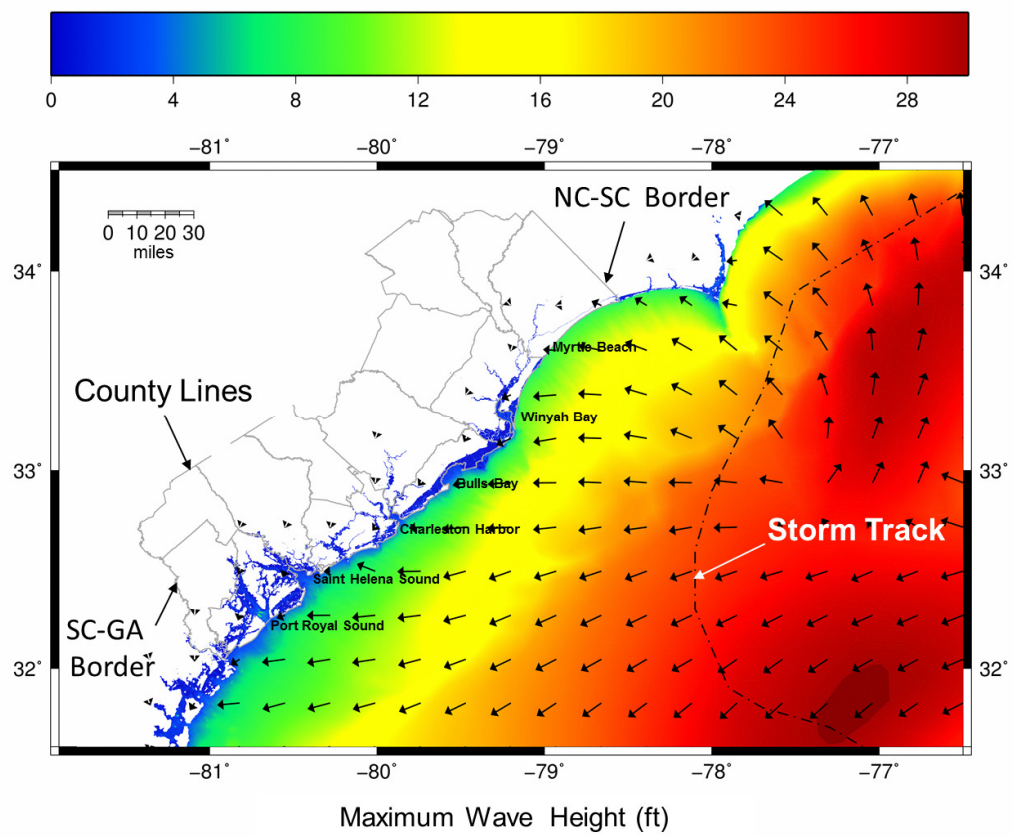

Figure 13: Maximum Wave Heights (ft) near South Carolina Simulated by SWAN+ADCIRC for Hurricane Ophelia. 


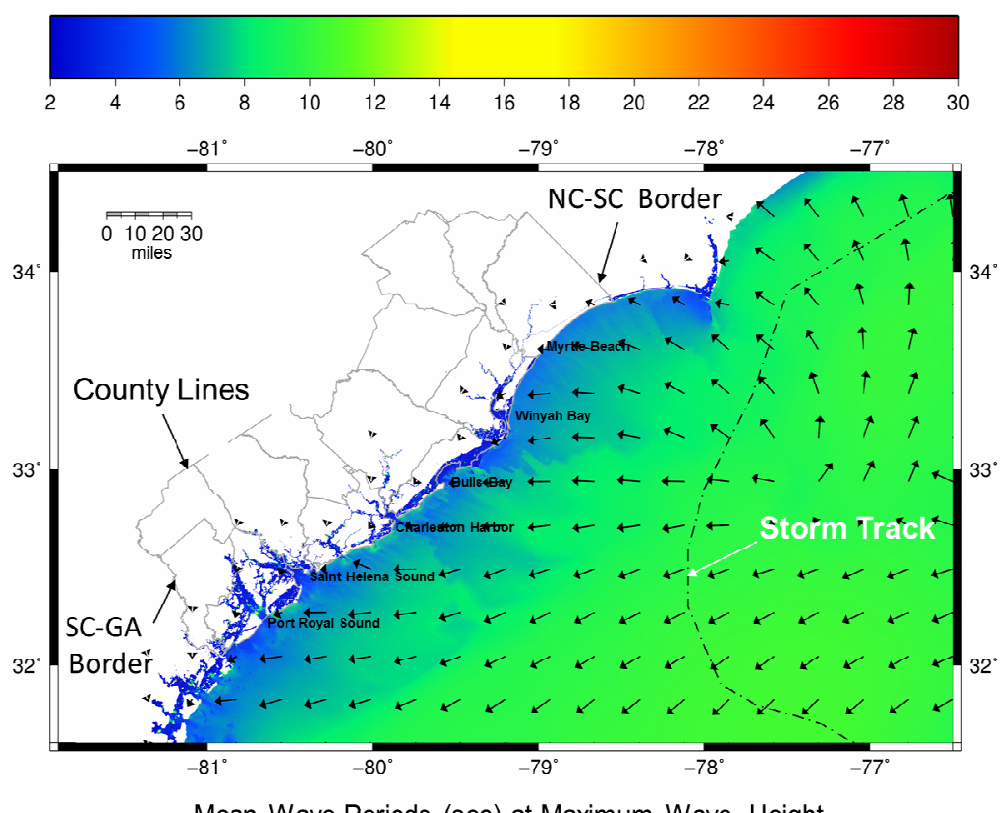

Mean Wave Periods (sec) at Maximum Wave Height

Figure 14: Mean Wave Periods (sec) at Maximum Wave Height near South Carolina Simulated by SWAN+ADCIRC for Hurricane Ophelia.

As with Hurricane Hugo, very limited wave measurement data exist near the South Carolina coast for Hurricane Ophelia. Measurements at NDBC Stations 41013 (Frying Pan Shoals, North Carolina, approximately $30 \mathrm{~nm}$ southeast of Southport, North Carolina) and 41004 (Edisto, $41 \mathrm{~nm}$ southeast of Charleston, South Carolina) provide measured wave height and period data during the passage of Hurricane Ophelia near the South Carolina coast. Station 41013 also provides measured wave direction data. Figure 8 shows the locations of the NDBC Stations applied in the Hurricane Ophelia model comparisons.

Figures 15 through 17 provide time series comparisons of the wave heights, peak periods, and mean directions for the NDBC Station 41013 measurements and the SWAN+ADCIRC simulation results. The timing of the models places Day 19 (on x-axis) at 12:00, September 11, 2005. Hurricane Ophelia passed near Station 41013; the station data indicate large wave heights and peak wave periods with mean wave directions moving toward the shore (generally west-northwest). The figures show good agreement between simulated and measured wave heights, peak periods, and directions during the fourday period of SWAN output.

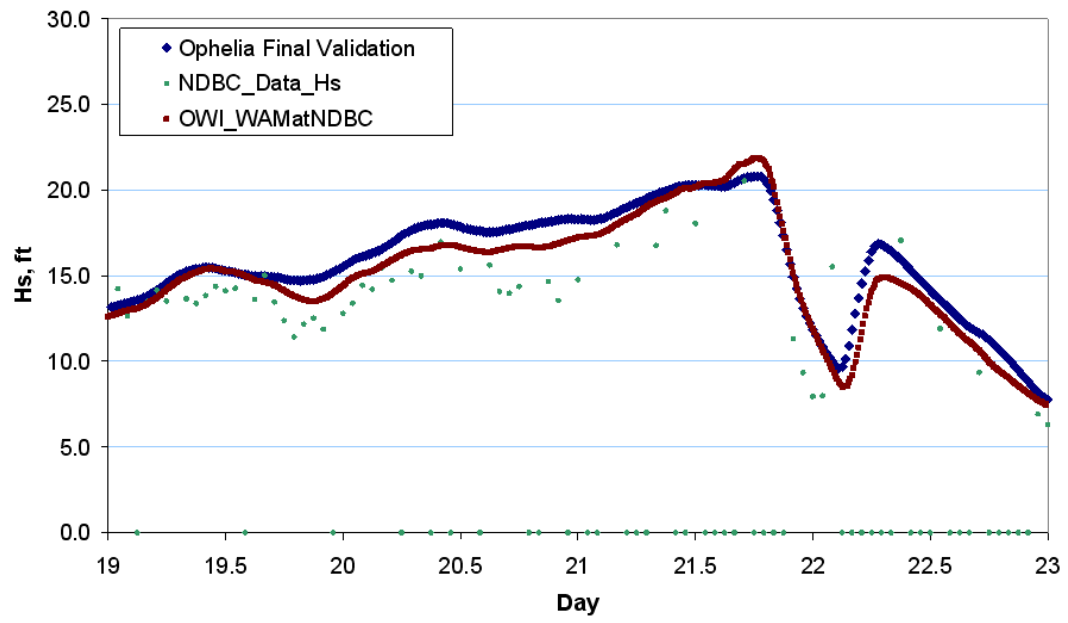

Figure 15: Comparison of SWAN+ADCIRC and WAM Simulation Results and NDBC Station 41013 Wave Height Measurements for Hurricane Ophelia. 


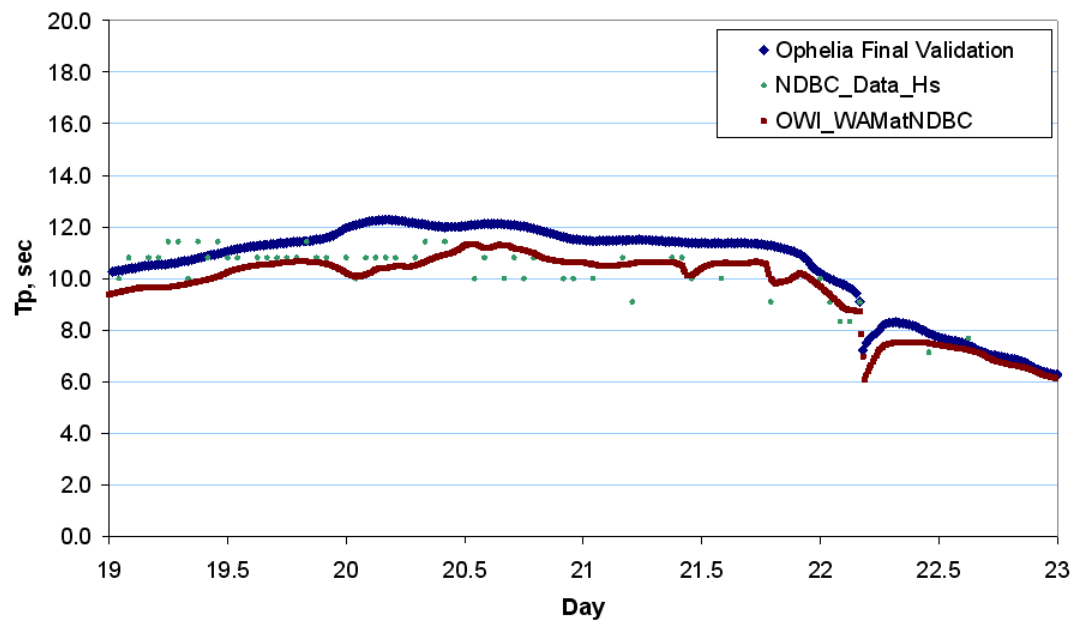

Figure 16: Comparison of SWAN+ADCIRC and WAM Simulation Results and NDBC Station 41013 Peak Wave Period Measurements for Hurricane Ophelia.

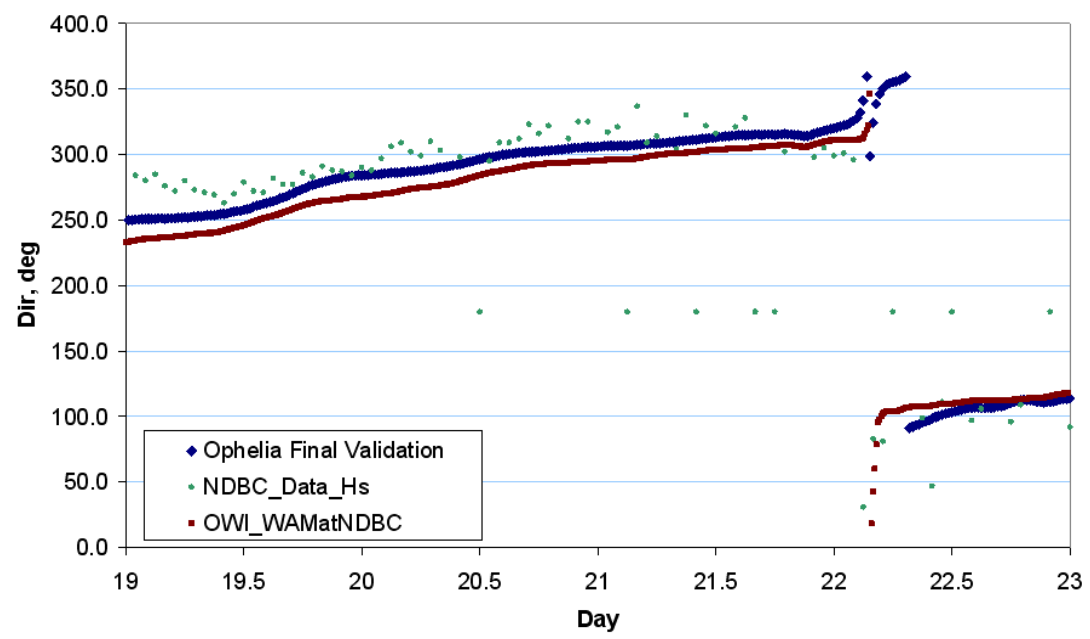

Figure 17: Comparison of SWAN+ADCIRC and WAM Simulation Results and NDBC Station 41013 Mean Wave Direction Measurements for Hurricane Ophelia.

Figures 18 and 19 provide time series comparisons of the wave heights and peak wave periods for the NDBC Station 41004 measurements and the SWAN+ADCIRC and OWI_WAM simulation results. Station 41004 did not provide a measured wave direction record during Hurricane Ophelia. Hurricane Ophelia passed well to the north of Station 41004; the station data indicate lower wave heights and generally lower peak periods than Station 41013 data. Figures 18 and 19 show good agreement between the SWAN+ADCIRC and OWI_WAM wave height and peak wave period values during the four-day period of SWAN output.

The University of South Carolina (USC) — data provided by Dr. George Voulgaris — collected nearshore wave data during Hurricane Ophelia at two locations - Folly Beach and Springmaid Pier. Springmaid Pier lies in the northeast portion of South Carolina, and Folly Beach lies further southwest in central South Carolina. The USC data allow comparison of the measured and simulated wave heights, peak periods, and mean wave directions at the two stations. According to the USC data, the Folly Beach and Springmaid Pier gauges occurred at water depths of approximately 14 and $21 \mathrm{ft}$. 


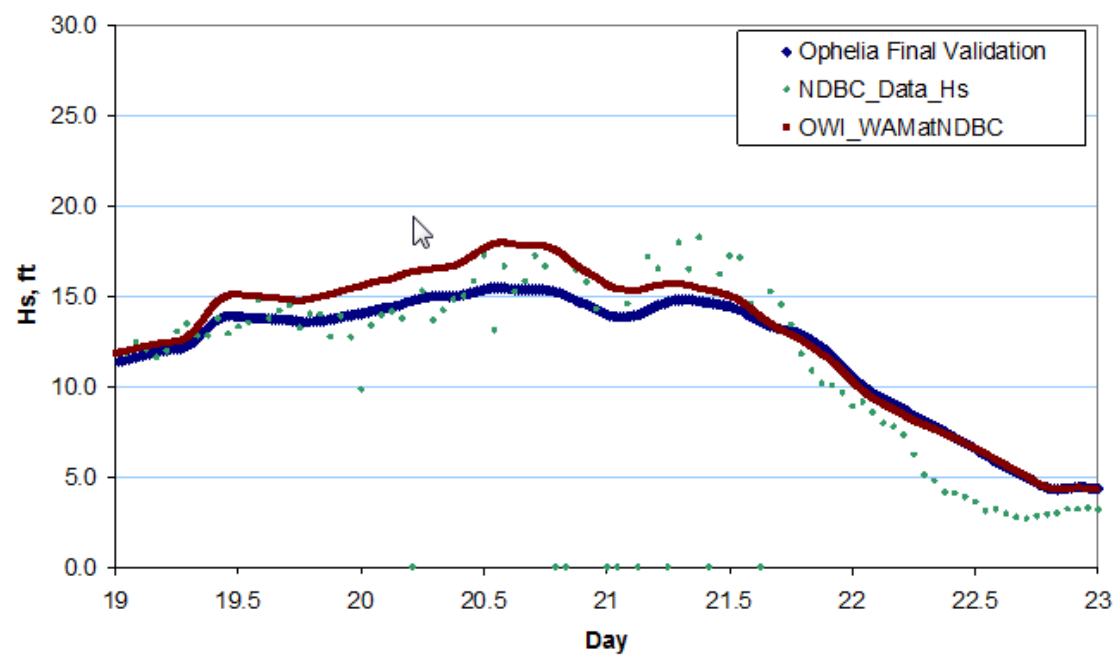

Figure 18: Comparison of SWAN+ADCIRC and WAM Simulation Results and NDBC Station 41004 Wave Height Measurements for Hurricane Ophelia.

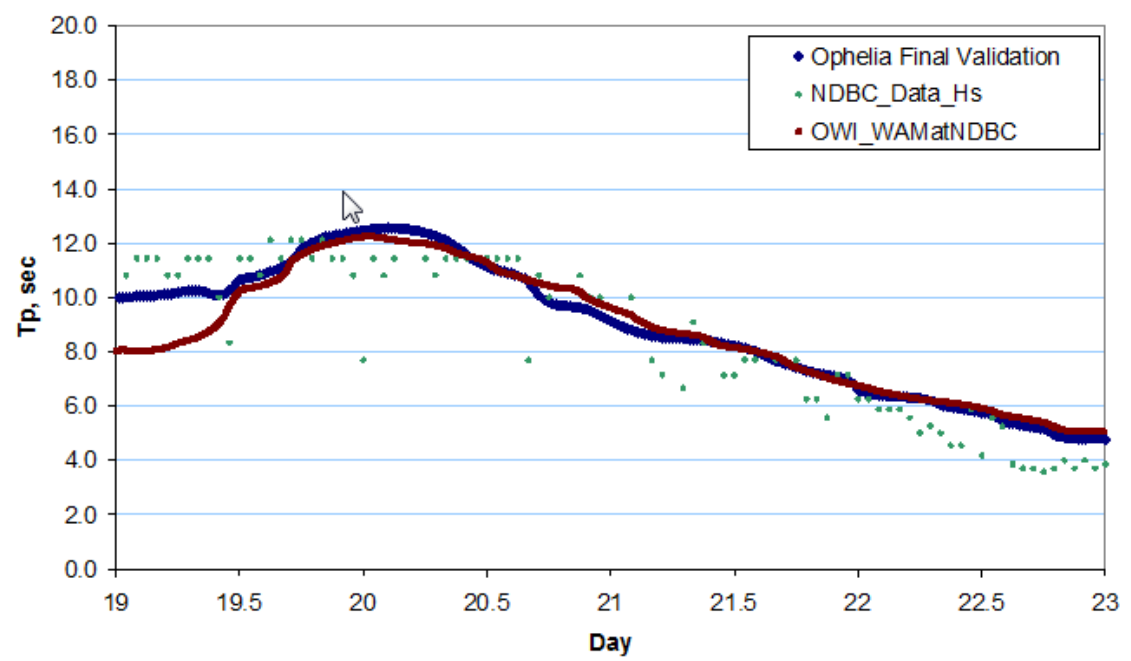

Figure 19: Comparison of SWAN+ADCIRC and WAM Simulation Results and NDBC Station 41004 Peak Wave Period Measurements for Hurricane Ophelia.

Figure 20 shows a plot of the measured and simulated wave heights at the Springmaid Pier gauge for a four-day period during Hurricane Ophelia. The figure shows results for SWAN with default JONSWAP — long period (swell) coefficient — bottom friction (Oph JON_Dt20_MaxItn6) and with the final validation settings with Madsen friction (Madsen et al., 1988) applied. The final settings apply the Madsen friction formulation with roughness lengths converted from Manning's $\mathrm{n}$ values assigned to the mesh from land classification data, with a minimum Manning's n value equal to 0.03 applied to develop the roughness length. Both sets of SWAN results overestimate the measured waves; however, the final validation setting reduces the difference by almost half. The simulation results and measurements all show variation in the wave heights influenced by the tidal signal with several peaks after the start of the comparison period. As the storm passes the coast and the wave heights diminish, the simulated values more closely match the measurements. The increased bottom friction coefficient in the final validation settings induces more dissipation over the wide South Carolina shelf — a process that leads to relatively small wave heights at Springmaid Pier (email correspondence with Dr. George Voulgaris, March 10, 2010).

Figure 21 shows a plot of the measured and simulated peak wave period at the Springmaid Pier gauge during Hurricane Ophelia. The figure shows good agreement between the simulated peak wave period values with significant scatter and lower values in the measurements. The scatter in the measurements suggests that both local seas and offshore swell may have influenced the gauge during 
this time. The SWAN results for the final validation setting generally show better agreement with the measured peak wave periods after the peak wave heights occur (Day 21 and after).

Measured and simulated mean wave directions at the Springmaid Pier gauge (not shown) during the 50-hour period during Hurricane Ophelia shows good agreement between the simulated mean direction values and the measured values. As the storm passes the coast, the mean wave direction values remain generally constant near 290 degrees (waves moving west-northwest). Application of the different bottom friction settings in SWAN results in insignificant changes to the mean wave direction. As the wind changes following the passage of the storm, the mean wave direction shifts further offshore.

Comparison between the USC measured Hurricane Ophelia wave data, and the SWAN model results shows model performance with the final validation setting (variable Madsen formulation with a minimum roughness $n=0.03$ ). The final validation settings with the variable Madsen formulation for bottom friction more closely matches the measured wave heights than the default friction setting (JONSWAP with swell coefficient). The bottom friction setting had little influence on the peak wave period and mean wave direction values simulated by SWAN. Lack of additional measurement locations during Hurricane Ophelia and for additional storms limits the ability to refine the friction coefficients applied through the Madsen formulation in SWAN. Notably, the extensive nearshore wave analysis conducted with the nearshore and inland data collected during Hurricanes Ike and Gustav provided the basis for the minimum value allowed in the Madsen friction coefficients.

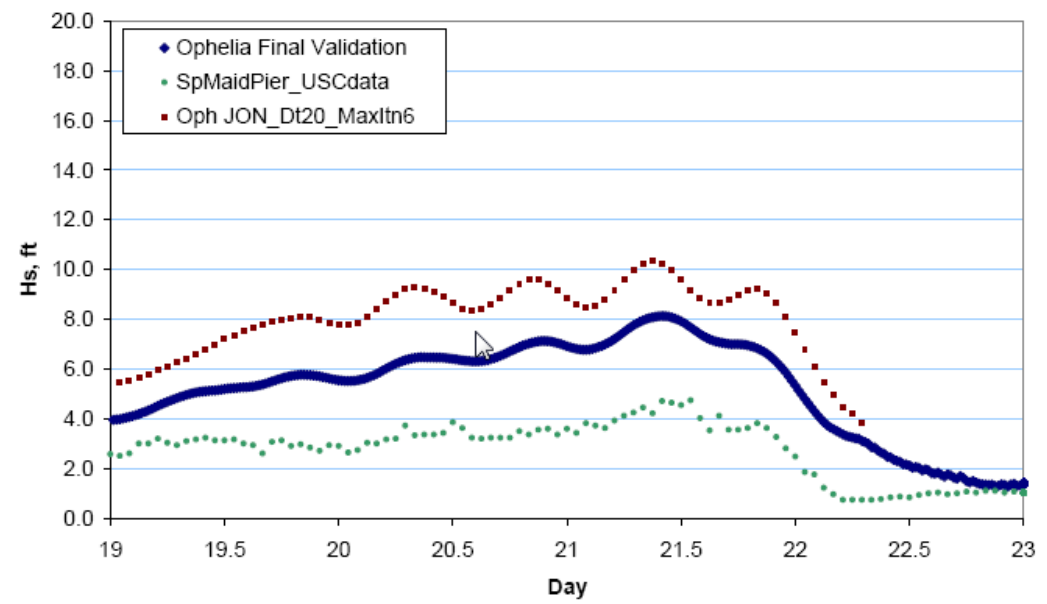

Figure 20. Comparison of SWAN+ADCIRC Simulation Results and USC Springmaid Pier Station Significant Wave Height Measurements for Hurricane Ophelia.

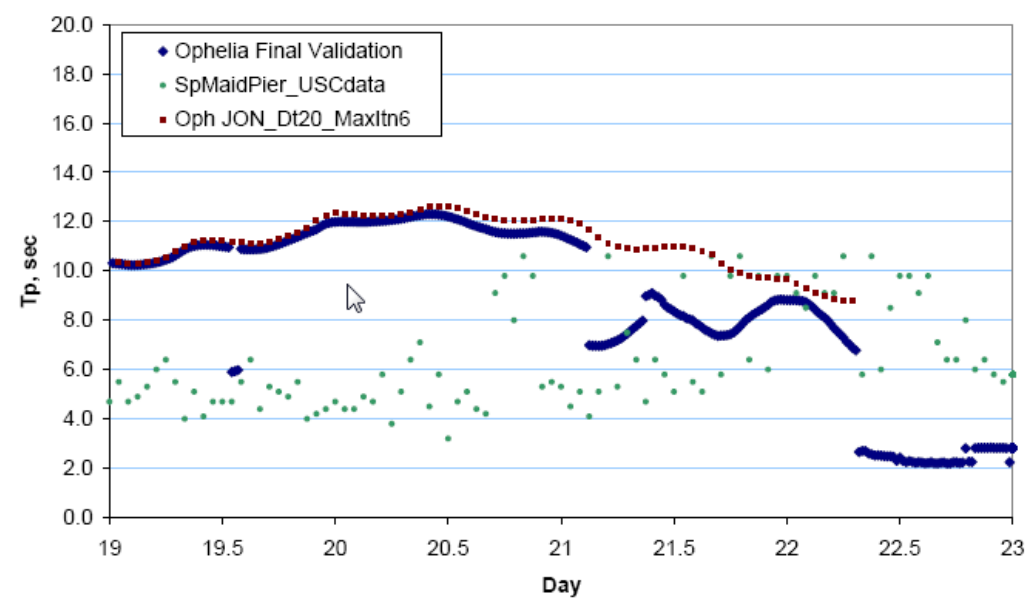

Figure 21. Comparison of SWAN+ADCIRC Simulation Results and USC Springmaid Pier Station Peak Wave Period Measurements for Hurricane Ophelia. 


\section{CONCLUSIONS}

The SCSS project applied the SWAN+ADCIRC model to develop offshore and nearshore wave simulations for hurricanes Hugo (1989) and Ophelia (2005) with comparisons to known available data. The SCSS project conducted additional simulations with a combined WAM (offshore) and STWAVE (nearshore) wave modeling system to provide additional simulation results. These simulations demonstrated that both model systems produce similar results.

Modeling of nearshore waves requires accurate wind forcing, accurate model bathymetry, suitable model boundary conditions, and robust, physics-based algorithms to develop and propagate the waves for given input wave conditions and wind forcing. The extreme wind forcing and wave transformation associated with hurricanes and tropical storms challenges the capabilities of the latest wave models to model nearshore waves. With only limited data sets available to document the development, propagation, and transformation of waves during these events, model performance during these events contains greater uncertainty than model performance during moderate events.

\section{ACKNOWLEDGMENTS}

agreement between the SWAN simulations and limited offshore and nearshore measurements. The SCSS project compared wave height, peak wave period, and mean wave direction values at selected offshore and nearshore points. Comparisons between simulations and limited nearshore data measured during Hurricane Ophelia (2005) show good agreement in the measured peak wave periods and mean wave directions with limited agreement in the wave heights. Application of the variable Madsen bottom friction formulation with a minimum roughness $(n=0.03)$ improved agreement between the SWAN results and the nearshore measurements. Uncertainty in the measured water depths and the limited capability of the wave models to reproduce the depth near the measurement station may account for some portion of the discrepancy. Additionally, some of the differences noted in the comparison plots of model results and measurements may derive from limitations in the modeled wind fields and within the wave model wind-wave growth, dissipation, and wave-wave interaction algorithms.

\section{ACKNOWLEDGMENTS}

The authors would like to thank Dr. George Voulgaris of the University of South Carolina for providing the nearshore wave data collected during Hurricane Ophelia at the Folly Beach and Springmaid Pier, SC stations.

\section{REFERENCES}

Booij, N., Ris, R.C. and Holthuijsen, L.H. 1999. A Third-Generation Wave Model for Coastal Regions, Part I, Model Description and Validation, Journal of Geophysical Research, C4, 104, 7649-7666.

Beven, J. and Cobb, H.D. 2005. Tropical Cyclone Report; Hurricane Ophelia, National Hurricane Center (NHC).

Dietrich, J.C., Zijlema, M., Westerink, J.J., Holthuijsen, L.H., Dawson, C., Luettich, R.A., Jensen, R., Smith, J.M., Stelling, G.S., and Stone, G.W. 2011. Modeling Hurricane Waves and Storm Surge using Integrally-Coupled, Scalable Computations, Coastal Engineering, 58, 45-65.

Dietrich, J.C., Zijlema, M., Allier, P-E., Holthuijsen, L.H., Booij, N., Meixner, J.D., Proft, J.K., Dawson, C.N., Bender, C.J., Naimaster, A., Smith, J.M., Westerink, J.J. In Revision. Limiters for Spectral Propagation Velocities in SWAN, Coastal Engineering, Revised Manuscript Submitted August 2012.

Luettich, R.A., Jr., Westerink, J.J., and Scheffner, N.W. 1992. ADCIRC: an Advanced ThreeDimensional Circulation Model for Shelves, Coasts, and Estuaries, Report 1: Theory and Methodology of ADCIRC-2DDI and ADCIRC03DL, Dredging Research Program Technical Report DRP-92-6, U.S. Army Engineers Waterways Experiment Station, Vicksburg, MS 137 p.

Madsen, O.S., Y.-K. Poon and H.C. Graber, 1988. Spectral wave attenuation by bottom friction: Theory, Proc. 21th Int. Conf. Coastal Engineering, ASCE, pp. 492-504.

National Hurricane Center (NHC). 1989. Preliminary Report for Hurricane Hugo. Website: http://www.nhc.noaa.gov/archive/storm_wallets/atlantic/atl1989-prelim/

Resio, D.T. and Westerink, J.J. 2008. Hurricanes and the Physics of Surges, Physics Today, 61, 9, 33-38.

Zijlema, M. 2010. Computation of Wind-Wave Spectra in Coastal Waters with SWAN on Unstructured Grids, Coastal Engineering, 57, 267-277. 